\title{
Convalescent plasma improves overall survival in patients with B-cell lymphoid malignancy and COVID-19: a longitudinal cohort and propensity score analysis
}

Thomas Hueso (1D ${ }^{1,2}{ }^{凶}$, Anne-Sophie Godron ${ }^{3}$, Emilie Lanoy ${ }^{4}$, Jérôme Pacanowski ${ }^{3}$, Laura I. Levi ${ }^{3}$, Emmanuelle Gras ${ }^{3}$, Laure Surgers ${ }^{3,4}$, Amina Guemriche $^{5}$, Jean-Luc Meynard ${ }^{3}$, France Pirenne ${ }^{6,7}$, Salim Idri' ${ }^{6}$, Pierre Tiberghien ${ }^{6,8}$, Pascal Morel (iD ${ }^{6}$, Caroline Besson (iD ${ }^{5,9}$, Rémy Duléry $\mathbb{D}^{10}$, Sylvain Lamure $\mathbb{D}^{11}$, Olivier Hermine ${ }^{12}$, Amandine Gagneux-Brunon ${ }^{13}$, Nathalie Freymond ${ }^{14}$, Sophie Grabar ${ }^{4,15}$ and Karine Lacombe (iD) $3,4 \bowtie$

(c) The Author(s), under exclusive licence to Springer Nature Limited 2022

Patients with hematological malignancy and COVID-19 display a high mortality rate. In such patients, immunosuppression due to underlying disease and previous specific treatments impair humoral response, limiting viral clearance. Thus, COVID-19 convalescent plasma (CCP) therapy appears as a promising approach through the transfer of neutralizing antibodies specific to SARS-CoV-2. We report the effect of CCP in a cohort of 112 patients with hematological malignancy and COVID-19 and a propensity score analysis on subgroups of patients with B-cell lymphoid disease treated $(n=81)$ or not $(n=120)$ with CCP between May 1,2020 and April 1 , 2021. The overall survival of the whole cohort was $65 \%(95 \% \mathrm{Cl}=56-74.9)$ and $77.5 \%(95 \% \mathrm{Cl}=68.5-87.7)$ for patients with $\mathrm{B}$-cell neoplasm. Prior anti-CD20 monoclonal antibody therapy was associated with better overall survival, whereas age, high blood pressure, and COVID-19 severity were associated with a poor outcome. After an inverse probability of treatment weighting approach, we observed in anti-CD20-exposed patients with B-cell lymphoid disease a decreased mortality of $63 \%(95 \% \mathrm{Cl}=31-80)$ in the CCP-treated group compared to the CCP-untreated subgroup, confirmed in the other sensitivity analyses. Convalescent plasma may be beneficial in COVID-19 patients with B-cell neoplasm who are unable to mount a humoral immune response.

Leukemia (2022) 36:1025-1034; https://doi.org/10.1038/s41375-022-01511-6

\section{NTRODUCTION}

Patients with hematological malignancy and SARS-CoV-2 infection display a high mortality rate with an estimated risk of death of $34 \%$ that reaches $39 \%$ in hospitalized patients [1, 2]. In such patients, several studies highlighted that both underlying cellular or humoral immunosuppression may hamper virus clearance resulting in prolonged shedding and a higher risk of severe COVID-19 [3, 4]. Furthermore, anti-SARS-CoV-2 vaccine response in patients with hematological malignancy is lower compared to the general population, especially in patients with B-cell lymphoid disease $[5,6]$. Thus, therapeutic approaches to inhibit viral replication and enhance viral clearance are mandatory in this specific population.
Early transfusion of high titer COVID-19 convalescent plasma (CCP) has emerged as a promising therapy to target SARS-CoV-2 and achieve clinical recovery [7-9]. In France, CCP has been proposed in a national monitored access program, notably to hospitalized COVID-19 patients with underlying immunosuppression such as patients with hematological malignancy. While most randomized trials have not reported a benefit of CCP in a general population with COVID-19 [10], we observed that B-cell depleted patients with protracted COVID-19 may benefit from CCP transfusion along with a decrease of all inflammatory parameters, oxygen weaning, and viral clearance [11]. Accordingly, a retrospective propensity score-matched analysis of 966 patients with a wide range of hematological malignancies, among whom 143

\footnotetext{
${ }^{1}$ Department of Hematology, Gustave Roussy, Villejuif, France. ${ }^{2}$ Paris-Saclay University, Paris, France. ${ }^{3}$ Infectious Diseases Department, Hôpital Saint Antoine, Assistance PubliqueHôpitaux de Paris (APHP), Paris, France. ${ }^{4}$ Sorbonne Université, Inserm, Institut Pierre Louis d'Épidémiologie et de Santé Publique (IPLESP), Paris, France. ${ }^{5}$ Department of Hematology, Hôpital André Mignot, Le Chesnay, France. ${ }^{6}$ Etablissement Français du Sang, La Plaine Saint-Denis, France. ${ }^{7}$ Institut Mondor de Recherche Biomédicale, Unité 955 , Equipe 2: Transfusion et Maladies du Globule Rouge, Inserm, Etablissement Français du Sang, Université Paris-Est Créteil, Créteil, France. ${ }^{8}$ UMR 1098 RIGHT Inserm Université de Franche-Comté, Etablissement Français du Sang, Besançon, France. ${ }^{9}$ Université de Versailles, Saint Quentin en Yvelines/Université Paris-Saclay, Inserm, Equipe “Exposome et Hérédité," CESP, Villejuif, France. ${ }^{10}$ Department of Hematology, Hôpital Saint Antoine, Assistance Publique-Hôpitaux de Paris (APHP), Paris, France. ${ }^{11}$ Department of Hematology, $\mathrm{CHU}$ de Montpellier, Montpellier, France. ${ }^{12}$ Laboratory of Molecular Mechanisms of Hematologic Disorders and Therapeutic Implications, Imagine Institute, Paris, France. ${ }^{13}$ Infectious Diseases Department, CHU de Saint-Etienne, Saint-Priest-en-Jarez, France. ${ }^{14}$ Pneumology Department, CHU Lyon Sud, Hospices Civils de Lyon, Lyon, France. ${ }^{15}$ Department of Public Health, Assistance Publique-Hôpitaux de Paris (APHP), Hôpital Saint Antoine, Paris, France. ${ }^{凶}$ email: thomas.hueso@aphp.fr; karine.lacombe2@aphp.fr
} 
CCP monitored access program

Patients with hematological malignancies treated by $\mathrm{CCP}$ $\mathrm{n}=112(\mathbf{C C P}$ cohort $)$

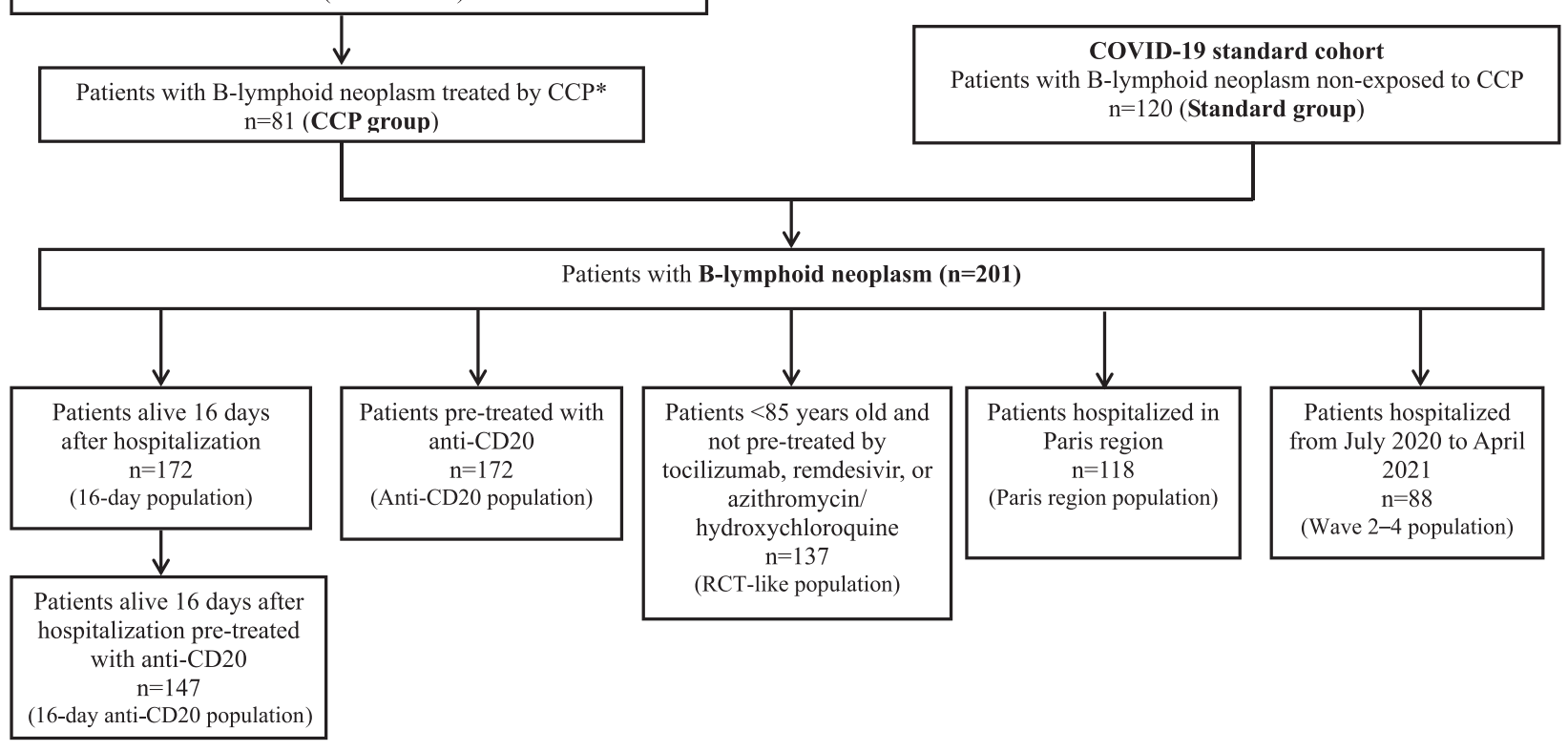

Fig. 1 Flowchart. *Excluding B-acute lymphoblastic leukemia $(n=2)$.

received $\mathrm{CCP}$, and reported that $\mathrm{CCP}$ transfusion was associated with $40 \%$ lower mortality [12], without taking into consideration immortal time bias and specificity of each hematological malignancy [13]. Building on these encouraging results, we report the outcome after CCP transfusion in a cohort of COVID-19 patients with hematological malignancy as well as on the results of a nested comparison of the survival among patients with B-cell neoplasm treated or not with CCP.

\section{METHODS \\ Patients and inclusion criteria}

We analyzed all patients with hematological malignancy and virologically documented COVID-19 included from May 1, 2020 to April 1, 2021 in a CCP monitored access program implemented in France (CCP cohort). Underlying disease included B-cell lymphoid neoplasm (such as diffuse B-cell lymphoma, chronic lymphocytic leukemia, follicular lymphoma, mantle cell lymphoma, marginal zone lymphoma, or B-acute lymphoblastic leukemia) and plasma-cell neoplasm requiring treatment and myeloid neoplasm (myelodysplastic syndrome or acute myeloid leukemia).

The subset of patients with B-lymphoid neoplasm in the CCP cohort was then compared in a propensity score analysis to a cohort of patients with the similar disease who were not treated with CCP in French hospitals during the same successive COVID-19 outbreak periods (Fig. 1). Both cohorts were treated as per the standard of care for COVID-19. Patients gave their written informed consent for the retrospective data collection, and ethical clearance was obtained from the French Infectious Diseases Society (IRB number: 00011642).

\section{Patient treatment and data collection}

All patients included in the CCP monitored access program received four ABO-compatible CCP units (200-220 mL each), usually two units/day over 2 days (day 0 and day +1 ) and more rarely one unit/day over 4 days. Most often, patients received CCP from four different donors. Convalescent donors were eligible for plasma donation 15 days after the resolution of COVID-19 symptoms. Collected apheresis plasma underwent pathogen reduction (Intercept blood system; Cerus, Concord, CA) and standard testing, as per current regulations in France. In addition, anti-SARS-CoV-2 antibody content was assessed in each donation, with a requirement for a SARS-CoV-2 seroneutralization titer $\geq 40$ ( $\geq 80$ after October 2020) and/or an immunoglobulin $\mathrm{G}$ enzyme-linked immunosorbent assay (EUROIMMUN, Bussy-Saint-Martin, France) ratio $>5.6$ ( $\geq 8$ after October 2020) [14].
Clinical parameters (temperature and oxygen need) as well as grading on the WHO scale for COVID-19 severity and biological parameters, including inflammatory markers (C-reactive protein (CRP), ferritin, fibrinogen, and D-dimers), were recorded at the time of CCP transfusion (day 0) [15]. SARS-CoV-2 serological status and circulating lymphocyte subpopulations at day 0 were assessed. PCR in the nasopharyngeal swab (with cycle threshold when available) was performed at day 0 and day +7 after CCP. Adverse events were recorded.

\section{Outcomes}

The primary outcomes were 90-day overall survival (OS) and factors associated with the risk of death in all patients with hematological malignancy and COVID-19 after CCP transfusion treated in the monitoring access program. Then, among patients with B-cell neoplasm, OS from the first day of hospitalization for COVID-19 of patients who received CCP (CCP group) was compared to the survival of those who did not (standard group). Secondary outcomes included safety and kinetics of inflammatory parameters after CCP transfusion.

\section{Statistics}

Continuous variables are described with their medians and interquartile ranges, whereas categorical variables are expressed as raw numbers and percentages. In the CCP cohort study, a Wilcoxon-paired test was performed to compare clinical and biological parameters at day 0 and day +7 after CCP transfusion. Ninety-day OS was evaluated using Kaplan-Meier estimates from the time of CCP transfusion. A log-rank test was used to compare survival curves. Crude and adjusted hazard ratios (HR) of death were estimated by univariable and multivariable Cox proportional hazard model. The multivariable model was built after stepwise selection of the variables from the variables with $p$ value below 0.05 in univariable regressions. Covariates considered in univariable analysis were gender, age ( $\geq 70$ years versus below), comorbidities (diabetes, high blood pressure, and body mass index), type of hematological malignancy, previous B-cell depletion therapy such as anti-CD20 or anti-CD19 monoclonal antibodies (mAbs), time between symptoms onset and CCP transfusion, and disease status (complete remission, partial remission/stable disease, and progressive disease).

To further evaluate the effectiveness of CCP, we compared the 81 CCPtreated B-cell neoplasm patients (after exclusion of 2 patients with B-acute lymphoblastic leukemia) of the CCP cohort to 120 CCP-untreated B-cell neoplasm patients from the cohort partly described in Dulery et al. study (standard group) [16]. To estimate the effect of CCP on survival in nonrandomized settings where patients' characteristics associated with CCP 
exposure could differ in the two groups, an inverse probability of treatment weighting (IPTW) approach was retained in an effort to control for indication bias in several population analyses. An individual propensity score (i.e., the probability of treatment by CCP) was retrieved from a logistic regression model, including potential confounders, both associated with prognostic of survival and CCP indication: age (" $<65$ years" vs. " $\geq 65$ years"), comorbidity (high blood pressure or diabetes or BMI $\geq 25 \mathrm{~kg} / \mathrm{m}^{2}$ yes vs. no), and corticosteroid therapy (yes vs. no). A pseudopopulation was built by weighting observations by propensity scores. In order to check if weighting improved the comparability of the two groups, absolute standardized differences were estimated in the unweighted and weighted samples. According to IPTW common practice, standardized differences $<0.20$ were considered negligible. For each analysis, the distribution of the probability of receiving CCP in the two groups was examined visually in order to see if overlap existed and the positivity assumption was not violated (Supplementary Fig. S1). Then, HRs of death associated with CCP were derived from weighted Cox proportional hazards. Estimates of HR of death associated with CCP from the univariable and multivariable (adjusted for variables included in the propensity score and described above) unweighted Cox proportional hazards model were also provided for the main and sensitivity analyses population. Of note, the number of variables included in both IPTW and multivariable models was limited by the relatively low number of events; therefore, only variables strongly associated with the indication of CCP and with sufficient numbers of patients for each modality were kept (Supplementary Fig. S2). The main analysis was restricted to patients with B-cell lymphoid disease previously treated with anti-CD20 therapy and who were alive 16 days after hospitalization for COVID-19, which corresponded to the median time of CCP transfusion after hospitalization. In order to limit the immortal time bias that can arise because patients treated with CCP had to survive long enough after hospitalization to receive CCP [13], a landmark approach was chosen. Follow-up of patients who received CCP after more than 16 days following hospitalization was censored at the time of CCP initiation. Since the use of CCP could differ in terms of area and period of recruitment, and exposure to cancer therapies and to COVID-19 medications that were not accounted for in IPTW, several sensitivity analyses in which baseline was the date of hospitalization were conducted to assess for the robustness of the main results: (i) in the overall population of patients exposed and nonexposed to CCP; (ii) in a population restricted to anti-CD20 therapy pretreated patients, excluding patients over 85 years, and patients preexposed to tocilizumab, remdesivir, or azithromycin/hydroxychloroquine; (iii) in a population excluding the first epidemic wave from March 2020 to June 2020; and (iv) in a population restricted to Paris region (Ile-de-France area, see Fig. 1 and Supplementary Table S1). Another sensitivity landmark analysis with baseline at the date of hospitalization plus 16 days has been carried out in patients alive 16 days after hospitalization. Of note, other sensitivity analyses on the overall population were also adjusted for gender. All analyses were done using $\mathrm{R}$ software version 3.6.1 and SAS Software version 9.4 (Cary, North Carolina, USA). A $p$ value below 0.05 denoted statistical significance.

\section{RESULTS}

\section{COVID-19 convalescent plasma cohort analysis}

One hundred and twelve patients ( $33 \mathrm{~F} / 79 \mathrm{M}$ ) aged 62.5 (range) (20-88) years with hematological malignancy and COVID-19 received CCP. Among them, 83 (74\%) patients were treated for B-lymphoid neoplasm, 10 (9\%) for myeloid neoplasm, and 19 (17\%) for multiple myeloma. Eighty-one (72\%) patients had received anti-CD20 or anti-CD19 targeted therapy at a median of 42 (interquartile range) (137-14) days before the first symptoms of COVID-19. Ninety-eight patients (87\%) patients had a negative SARS-CoV-2 serology at the time of CCP transfusion. The median circulating B-lymphocytes count was 0 (interquartile range) (0-0)/ $\mathrm{mm}^{3}$ in 58 evaluable patients with B-cell lymphoid disease, 9 $(0-48) / \mathrm{mm}^{3}$ in 6 patients with myeloid neoplasm, and $7(1-17) /$ $\mathrm{mm}^{3}$ in 9 patients with plasma-cell neoplasm. Of note, $11 / 83$ (13\%) patients with B-lymphoid neoplasm, 2/10 (20\%) with myeloid neoplasm, and 8/19 (42\%) with plasma-cell neoplasm were mechanically ventilated (WHO scale 7), at the time of CCP transfusion. Previous COVID-19 treatments included corticosteroids $(n=72,64 \%)$, tocilizumab $(n=8,7 \%)$, and remdesivir $(n=13$,
Table 1. COVID-19 convalescent plasma (CCP) cohort characteristics.

\begin{tabular}{|c|c|}
\hline Patient characteristics & $\begin{array}{l}\text { Patients } \\
n=112\end{array}$ \\
\hline Age, mean (range) & $62.5(20-88)$ \\
\hline B-lymphoid neoplasm, n (\%) & $83(74)$ \\
\hline Diffuse large B-cell lymphoma & $28(25)$ \\
\hline Follicular lymphoma & $23(20)$ \\
\hline Mantle cell lymphoma & $11(10)$ \\
\hline Marginal zone lymphoma & $4(3)$ \\
\hline Chronic lymphocytic leukemia & $13(12)$ \\
\hline Waldenström macroglobulinemia & $2(2)$ \\
\hline B-acute lymphoblastic leukemia & $2(2)$ \\
\hline Myeloid neoplasm, n (\%) & $10(9)$ \\
\hline Myelodysplastic syndrome & $2(2)$ \\
\hline Acute myeloid leukemia & $8(7)$ \\
\hline Plasma-cell neoplasm, $n$ (\%) & $19(17)$ \\
\hline Previous anti-CD19 or anti-CD20 mAbs, $n$ (\%) & $81(72)$ \\
\hline Previous anti-CD38 mAbs, $n$ (\%) & $10(9)$ \\
\hline $\begin{array}{l}\text { Median time between last anti-CD19 or anti-CD20 mAbs } \\
\text { and COVID-19, days (IQR) }\end{array}$ & $42(137-14)$ \\
\hline \multicolumn{2}{|l|}{ Previous stem cell transplantation, $n(\%)$} \\
\hline Autologous & $27(25)$ \\
\hline Allogeneic & $5(4)$ \\
\hline \multicolumn{2}{|l|}{ Disease status at the time of COVID-19, $n$ (\%) } \\
\hline Complete remission & $48(43)$ \\
\hline Partial remission/stable disease & $29(25)$ \\
\hline Progressive disease & $22(20)$ \\
\hline Missing data & $13(12)$ \\
\hline \multicolumn{2}{|c|}{ B-lymphocyte count at the time of CCP transfusion, median (IQR) } \\
\hline B-lymphoid neoplasm & $0(0-0)$ \\
\hline Myeloid neoplasm & $9(0-48)$ \\
\hline Plasma-cell neoplasm & $7(1-17)$ \\
\hline \multicolumn{2}{|l|}{ Serological status for COVID-19, $n$ (\%) } \\
\hline Positive & $2(2)$ \\
\hline Negative & $98(87)$ \\
\hline Unknown & $12(11)$ \\
\hline \multicolumn{2}{|l|}{ Previous COVID-19-specific treatment, $n(\%)^{\mathrm{a}}$} \\
\hline Steroid & $72(64)$ \\
\hline Tocilizumab & $8(7)$ \\
\hline Remdesivir & $13(12)$ \\
\hline Others & $8(7)$ \\
\hline Nothing & $32(29)$ \\
\hline
\end{tabular}

$m A b s$ monoclonal antibodies, IQR interquartile range.

${ }^{a}$ Some patients may have simultaneous treatment.

$12 \%)$. No patients received anti-spike mAbs or were vaccinated. The remaining patient characteristics are described in Table 1.

Transfusion-related adverse events were reported in a limited number of patients and included three allergies (two minor, one severe) and two cases of transient increase in oxygen requirement of uncertain imputability. CCP transfusion was associated with decreased $(\mathrm{d}+7$ vs. $\mathrm{d} 0)$ temperature $(p<0.0001)$, CRP $(p<0.0001)$, ferritin $(p<0.0001)$, and fibrinogen $(p=0.026)$. Conversely, PCR cycle threshold values significantly increased $(p=0.00015)$ (Fig. 2). 


\section{Day 甶 0 甶 +7}
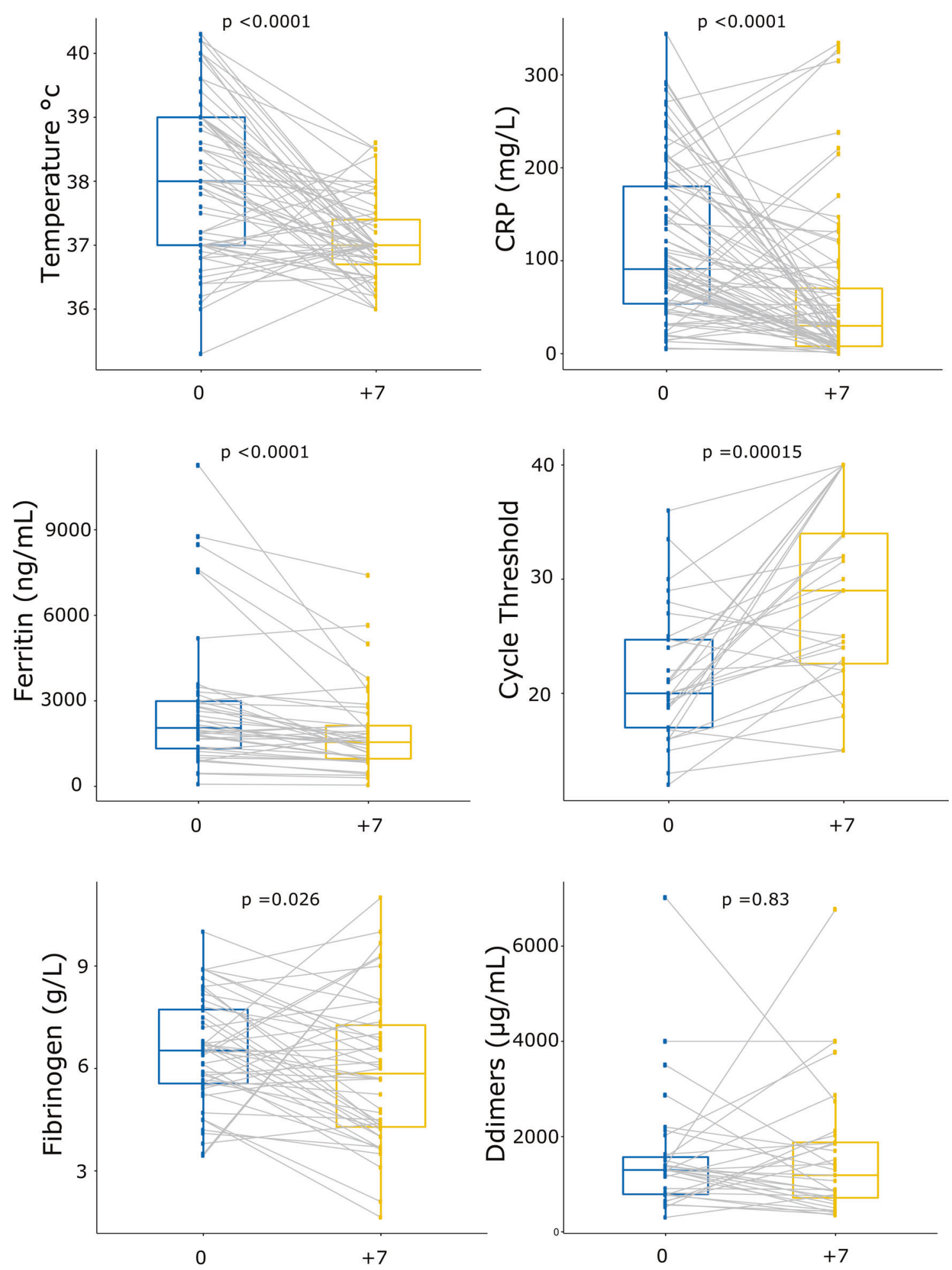

Fig. 2 Kinetics of clinical and inflammatory parameters. All parameters were assessed on the day of convalescent plasma transfusion (day 0 ) and 7 days after (day +7$)$. A cycle threshold value over 40 was considered negative. A Wilcoxon-paired test was assessed. The median and interquartile ranges are represented. 
Table 2. Univariable analysis.

\begin{tabular}{|c|c|c|c|c|c|c|}
\hline \multirow[b]{2}{*}{$\begin{array}{l}\text { Patient } \\
\text { characteristics }\end{array}$} & \multicolumn{4}{|c|}{ 90-day overall survival } & \multirow[b]{2}{*}{$95 \% \mathrm{Cl}$} & \multirow[b]{2}{*}{$P$} \\
\hline & $n=112$ & $\%$ & $95 \% \mathrm{Cl}$ & HR & & \\
\hline Overall & 112 & 64.9 & $56.2-74.9$ & & & \\
\hline Gender & & & & & & 0.02 \\
\hline Female & 33 & 79.7 & $66.1-96.0$ & 0.38 & $0.16-0.90$ & \\
\hline Male & 79 & 58.9 & $48.7-71.3$ & 1 & & \\
\hline Age & & & & & & 0.006 \\
\hline$<70$ years & 77 & 70.9 & $60.6-83.0$ & 1 & & \\
\hline$\geq 70$ years & 35 & 50.2 & $36-70.2$ & 2.41 & $1.26-4.60$ & \\
\hline $\begin{array}{l}\text { High blood } \\
\text { pressure }\end{array}$ & & & & & & 0.003 \\
\hline Yes & 20 & 42.9 & $25.5-72$ & 2.77 & $1.37-5.62$ & \\
\hline No & 92 & 69.5 & $60.2-80.3$ & 1 & & \\
\hline Diabetes & & & & & & 0.216 \\
\hline Yes & 7 & 42.9 & $18.2-100$ & 1.93 & $0.68-5.44$ & \\
\hline No & 105 & 66.7 & $57.9-76.9$ & 1 & & \\
\hline $\begin{array}{l}\text { Body mass } \\
\text { index }\end{array}$ & & & & & & 0.05 \\
\hline$<25$ & 52 & 59.7 & $47.4-75.2$ & 1 & & \\
\hline $25-30$ & 32 & 77.6 & $64.2-93.7$ & 0.48 & $0.2-1.13$ & \\
\hline$\geq 30$ & 12 & 23.3 & $5.1-100$ & 1.68 & $0.71-3.99$ & \\
\hline Missing data & 16 & 80.4 & $62.7-100$ & 0.44 & $0.13-1.49$ & \\
\hline $\begin{array}{l}\text { Hematological } \\
\text { diseases }\end{array}$ & & & & & & $<0.0001$ \\
\hline $\begin{array}{l}\text { B-lymphoid } \\
\text { neoplasm }\end{array}$ & 83 & 77.5 & $68.5-87.7$ & 1 & & \\
\hline $\begin{array}{l}\text { Myeloid } \\
\text { neoplasm }\end{array}$ & 10 & 20.0 & $5.8-69.1$ & 7.79 & $3.26-18.61$ & \\
\hline $\begin{array}{l}\text { Plasma-cell } \\
\text { neoplasm }\end{array}$ & 19 & 36.8 & $20.4-66.4$ & 4.6 & $2.17-9.78$ & \\
\hline $\begin{array}{l}\text { Previous anti- } \\
\text { CD20/CD19 } \\
\text { mAbs }\end{array}$ & & & & & & $<0.0001$ \\
\hline Yes & 81 & 76.9 & $67.7-87.4$ & 0.21 & $0.11-0.42$ & \\
\hline No & 31 & 35.5 & $22.1-57$ & 1 & & \\
\hline Disease status & & & & & & 0.8 \\
\hline $\begin{array}{l}\text { Complete } \\
\text { remission }\end{array}$ & 48 & 66.5 & $53.8-82.2$ & 1 & & \\
\hline $\begin{array}{l}\text { Partial } \\
\text { remission/ } \\
\text { stable disease }\end{array}$ & 29 & 68.1 & $52.9-87.7$ & 1 & $0.44-2.30$ & \\
\hline $\begin{array}{l}\text { Progressive } \\
\text { disease }\end{array}$ & 22 & 56.4 & $38.5-82.7$ & 1.45 & $0.63-3.38$ & \\
\hline Missing data & 13 & 69.2 & $48.2-99.5$ & 1 & $0.33-3.04$ & \\
\hline $\begin{array}{l}\text { WHO scale } \\
\text { (COVID- } \\
19 \text { severity) }\end{array}$ & & & & & & 0.0004 \\
\hline WHO 4 & 22 & 90 & $77.8-100$ & 1 & & \\
\hline WHO 5 & 47 & 71.7 & $59.8-86$ & 3.35 & $0.76-14.85$ & \\
\hline WHO 6 & 22 & 50 & $30.4-82.2$ & 4.86 & $1.05-22.55$ & \\
\hline WHO 7 & 21 & 38.1 & $22.1-65.7$ & 10.9 & $2.45-48.48$ & \\
\hline $\begin{array}{l}\text { Steroid } \\
\text { administration }\end{array}$ & & & & & & 0.8 \\
\hline Yes & 72 & 63.7 & $53.2-76.3$ & 1.12 & $0.56-2.23$ & \\
\hline No & 40 & 67.5 & $53.6-84.9$ & 1 & & \\
\hline $\begin{array}{l}\text { Time from } \\
\text { COVID-19 onset } \\
\text { to CCP }\end{array}$ & & & & & & 0.002 \\
\hline$<10$ days & 29 & 43.4 & $28.3-66.8$ & 1 & & \\
\hline$>10$ days & 83 & 72.8 & $63.3-83.6$ & 0.37 & $0.20-0.72$ & \\
\hline
\end{tabular}

A.
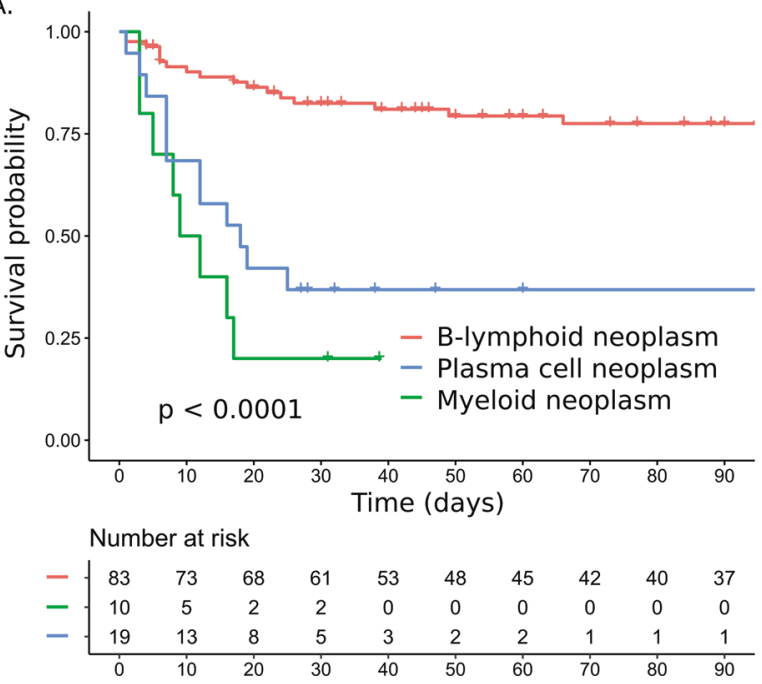

B.

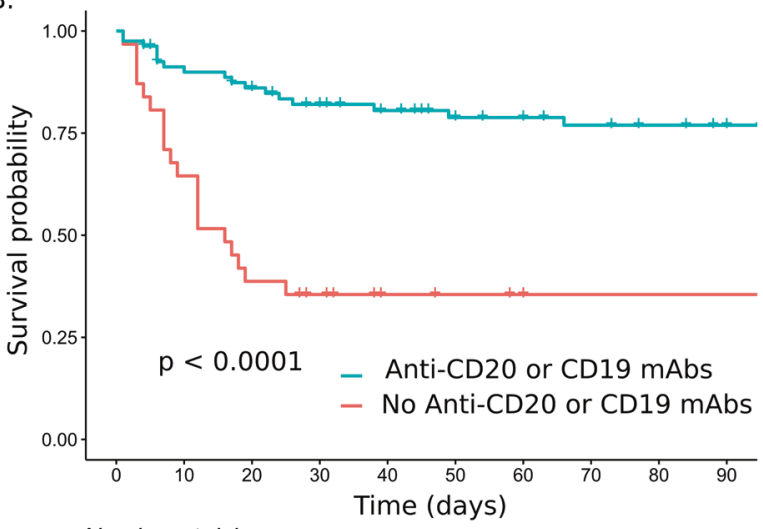

Number at risk

$-$\begin{tabular}{cccccccccc}
31 & 20 & 12 & 9 & 5 & 4 & 3 & 2 & 2 & 2 \\
81 & 71 & 66 & 59 & 51 & 46 & 44 & 41 & 39 & 36 \\
\hline 0 & 10 & 20 & 30 & 40 & 50 & 60 & 70 & 80 & 90
\end{tabular}

C.

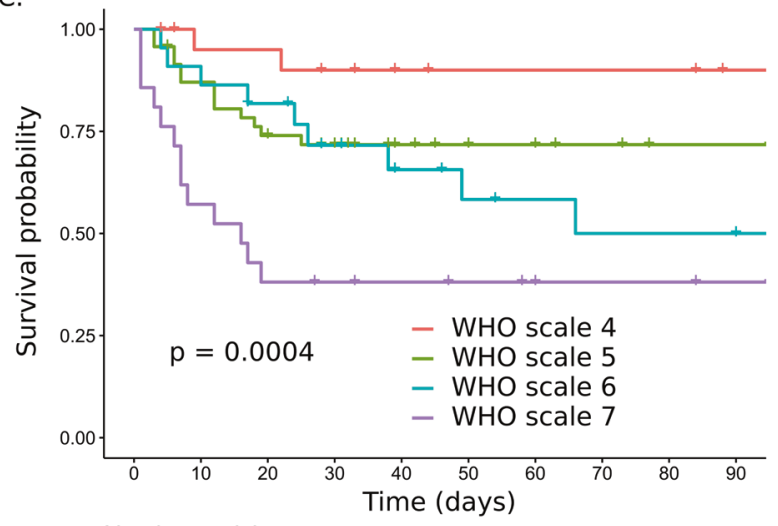

Number at risk

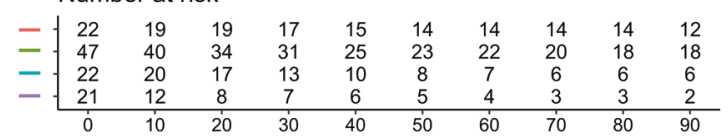

Fig. 3 Overall survival after COVID-19 convalescent plasma transfusion. Kaplan-Meier method was used according to the type of hematological malignancy (A); the exposition to anti-CD20 or anti-CD19 monoclonal antibodies (mAbs) (B); and the COVID-19 severity (WHO scale) (C). 


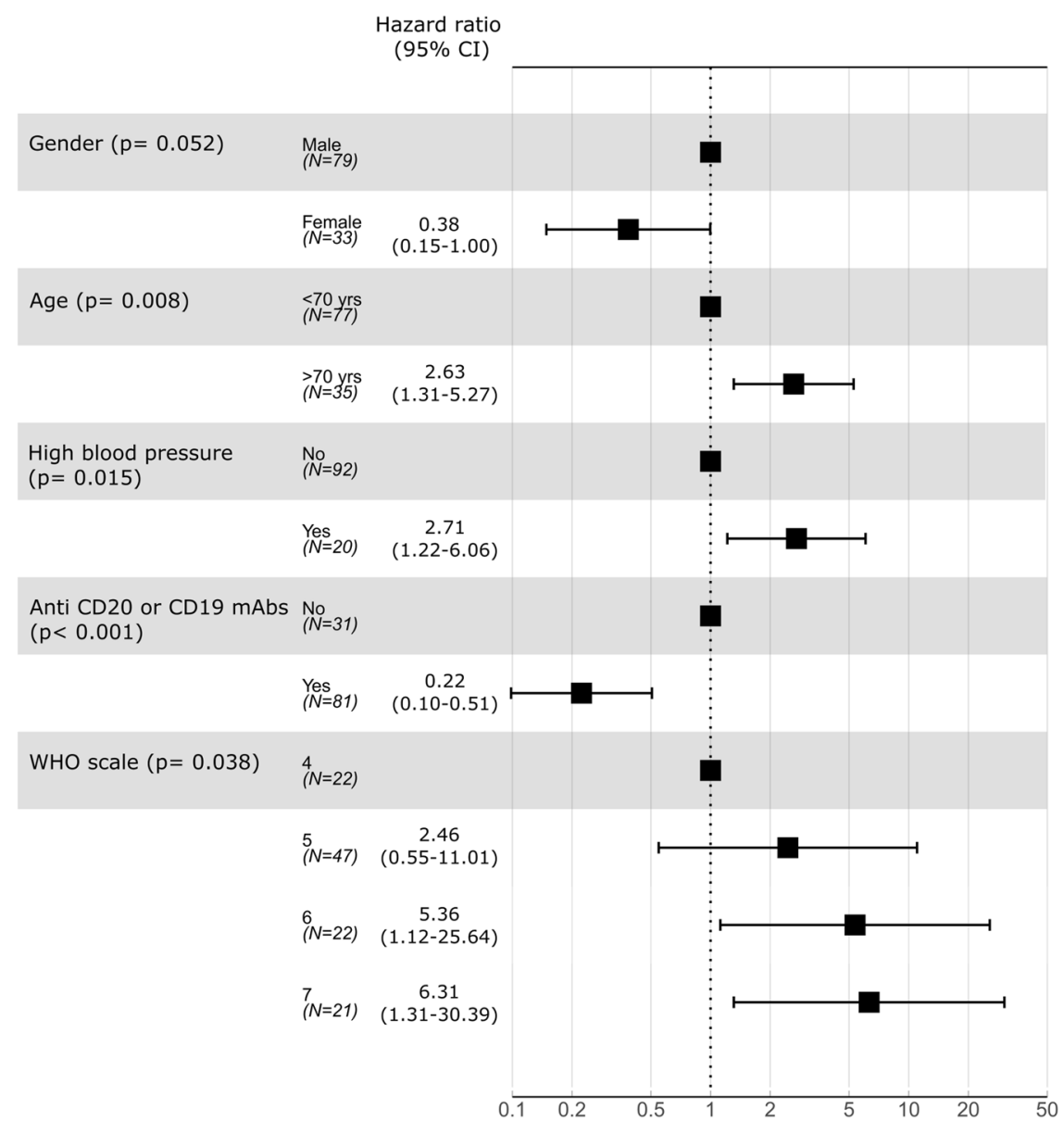

Fig. 4 Forest plot representing hazard ratio (HR) of death obtained in multivariable analysis. mAbs monoclonal antibodies.

The 90-day OS of whole cohort was $64.9 \%(95 \% \mathrm{Cl}=56.2-74.9)$, $77.5 \%(95 \% \mathrm{Cl}=68.5-87.7)$ in patients with B-lymphoid neoplasm, $20 \%(95 \% \mathrm{Cl}=5.8-69.1)$ with myeloid neoplasm, and $36.8 \%(95 \%$ $\mathrm{Cl}=20.4-66.4)$ with plasma-cell neoplasm. Deaths were all associated with COVID-19. In univariable analysis, age $>70$ years $(p=0.006)$, high blood pressure $(p=0.003)$, the type of hematological disease $(p<0.0001)$, a previous anti-CD20/CD19 mAbs $(p<$ $0.0001)$, COVID-19 severity $(p=0.0004)$, and the time of CCP administration $(p=0.002)$ were significantly associated with OS (Table 2 and Fig. 3). In multivariable analysis, only age $>70$ years $(\mathrm{HR}=2.63,95 \% \mathrm{Cl}=1.31-5.27 ; p=0.008)$, high blood pressure $(\mathrm{HR}=2.71,95 \% \mathrm{Cl}=1.22-6.06 ; p=0.015)$, and COVID-19 severity (WHO scale 6 and 7$)(\mathrm{HR}=5.36,95 \% \mathrm{Cl}=1.12-25.64$ and $\mathrm{HR}=$ $6.31,95 \% \mathrm{Cl}=1.31-30.39 ; p=0.038$, respectively) were associated with lower OS, whereas previous anti-CD20/CD19 mAbs was strongly associated with better $\mathrm{OS}(\mathrm{HR}=0.22,95 \% \mathrm{Cl}=0.10-0.51$; $p<0.001$ ) (Fig. 4).

\section{Propensity score analysis in patients with B-lymphoid neoplasm}

The numbers of patients included in each population analysis are provided in the flowchart in Fig. 1. The main population analysis included 147 patients pre-exposed to anti-CD20 therapy and alive on day 16 after hospitalization for COVID (Table 3).

The characteristics of patients of each analyzed population are detailed in Supplementary Table S1. This table shows that patients treated with CCP differ from the untreated ones, including for variables that could not be included in the propensity score. To account for the latter variables, sensitivity analysis populations restricted to specific wave, to pre-exposure to anti-CD20, or to the specific area of hospitalization were performed.

In the main IPTW analysis, the exposure to CCP was associated with a $63 \%(95 \% \mathrm{Cl}=31-80)$ decrease in the risk of death in the 16-day anti-CD20 pre-exposed population. The HR estimated by IPTW varied across the different analysis populations from $40 \%$ in the waves $2-4$ population to $63 \%$ in the main analysis population as shown in Fig. 5. Multivariable models provided similar results to IPTW (Supplementary Table S2). The addition of gender to the propensity score did not modify the estimation of the effect of the convalescent plasma exposure. HR of death associated with each variable included in the propensity score are provided in Supplementary Table S3.

\section{DISCUSSION}

Our study reports the effect of CCP in a large and representative cohort of patients with hematological malignancy and who were hospitalized for severe COVID-19. Overall, 90-day survival was $64.9 \%$ for the whole cohort and $77.9 \%$ in the B-cell neoplasm subgroup with an OS benefit estimated between $43 \%$ and $63 \%$ after IPTW approach supporting the results of the Thompson et al. study [12]. We also report a significant decrease of all inflammatory parameters as well as negativation of the nasopharyngeal PCR swab at $d+7$, consistent with our previous report [11]. Furthermore, CCP infusion was well tolerated [17]. As previously described, age and comorbidities such as high blood pressure and COVID-19 severity emerged as the most important risk factors of death due to COVID-19 [18]. Interestingly, although an increased 
Table 3. Characteristics of patients with B-lymphoid neoplasm according to analyzed population (main analysis and overall population analyses).

\begin{tabular}{|c|c|c|c|c|}
\hline & \multicolumn{4}{|c|}{ Analyzed population } \\
\hline & \multicolumn{2}{|c|}{$\begin{array}{l}\text { 16-day anti-CD20 } \\
\text { population }\end{array}$} & \multicolumn{2}{|c|}{ Overall population } \\
\hline & \multicolumn{2}{|l|}{ Group } & \multicolumn{2}{|l|}{ Group } \\
\hline & $\begin{array}{l}\text { CP+ } \\
N(\%)\end{array}$ & $\begin{array}{l}\text { CP- } \\
N(\%)\end{array}$ & $\begin{array}{l}\text { CP+ } \\
N(\%)\end{array}$ & $\begin{array}{l}\text { CP- } \\
N(\%)\end{array}$ \\
\hline All & $32(100)$ & $115(100)$ & $81(100)$ & $120(100)$ \\
\hline \multicolumn{5}{|l|}{ Epidemic wave } \\
\hline 1st-Mar-Jun 2020 & $2(6)$ & $81(71)$ & $19(23)$ & $94(77)$ \\
\hline 2nd-Jul-Oct 2020 & $8(25)$ & $20(17)$ & $26(32)$ & $10(8)$ \\
\hline 3rd-Nov-Dec 2020 & $18(56)$ & $13(11)$ & $32(40)$ & $11(9)$ \\
\hline 4th-Jan-Apr 2021 & $4(13)$ & $1(1)$ & $4(5)$ & $5(4)$ \\
\hline \multicolumn{5}{|l|}{ Geographic area } \\
\hline Paris region & $13(41)$ & $69(60)$ & $33(41)$ & $85(71)$ \\
\hline Eastern France & $1(3)$ & $26(23)$ & $9(11)$ & $30(25)$ \\
\hline Other & $18(56)$ & $20(17)$ & $39(48)$ & $5(4)$ \\
\hline \multicolumn{5}{|l|}{ Gender } \\
\hline Male & $19(59)$ & $76(66)$ & $56(69)$ & $72(60)$ \\
\hline Female & $13(41)$ & $39(34)$ & $25(31)$ & $48(40)$ \\
\hline \multicolumn{5}{|l|}{ Age (years) } \\
\hline$<55$ & $9(28)$ & $17(15)$ & $18(22)$ & $11(9)$ \\
\hline $55-64$ & $11(35)$ & $41(36)$ & $27(33)$ & $35(29)$ \\
\hline $65-74$ & $9(28)$ & $37(32)$ & $24(30)$ & $36(30)$ \\
\hline$\geq 75$ & $3(9)$ & $20(17)$ & $12(15)$ & $38(32)$ \\
\hline \multicolumn{5}{|l|}{$B M I\left(\mathrm{~kg} / \mathrm{m}^{2}\right)$} \\
\hline$<18.5$ & $2(6)$ & $5(4)$ & $3(4)$ & $6(5)$ \\
\hline$[18.5 ; 25]$ & $14(44)$ & $56(49)$ & $34(41)$ & $61(51)$ \\
\hline$[25 ; 30]$ & $10(31)$ & $29(25)$ & $24(30)$ & $29(24)$ \\
\hline$\geq 30$ & $4(13)$ & $15(13)$ & $8(10)$ & $17(14)$ \\
\hline Missing & $2(6)$ & $10(9)$ & $12(15)$ & $7(6)$ \\
\hline \multicolumn{5}{|l|}{ Arterial hypertension } \\
\hline No & $27(84)$ & $80(70)$ & $69(85)$ & $70(58)$ \\
\hline Yes & $5(16)$ & $35(30)$ & $12(15)$ & $50(42)$ \\
\hline \multicolumn{5}{|l|}{ Diabetes } \\
\hline No & $30(94)$ & $98(85)$ & $76(94)$ & $93(77)$ \\
\hline Yes & $2(6)$ & $17(15)$ & $5(6)$ & $27(23)$ \\
\hline \multicolumn{5}{|c|}{$A H$ or diabetes or $B M I>25 \mathrm{~kg} / \mathrm{m}^{2}-\mathrm{PS}^{*}$} \\
\hline No & $14(44)$ & $52(45)$ & $41(51)$ & $45(38)$ \\
\hline Yes & $18(56)$ & $63(55)$ & $40(49)$ & $75(63)$ \\
\hline \multicolumn{5}{|c|}{ WHO scale at hospitalization } \\
\hline Missing & $0(0)$ & $2(2)$ & $0(0)$ & $6(5)$ \\
\hline WHO 4 & $8(25)$ & $41(36)$ & $29(36)$ & $33(28)$ \\
\hline WHO 5 & $22(69)$ & $58(50)$ & $44(55)$ & $69(57)$ \\
\hline WHO 6 & $2(6)$ & $7(6)$ & $6(7)$ & $6(5)$ \\
\hline WHO 7 & $0(0)$ & $7(6)$ & $2(2)$ & $6(5)$ \\
\hline \multicolumn{5}{|l|}{ Anti-CD20 mAbs } \\
\hline No & $0(0)$ & $0(0)$ & $3(4)$ & $26(22)$ \\
\hline Yes & $32(100)$ & $115(100)$ & $78(96)$ & $94(78)$ \\
\hline \multicolumn{5}{|l|}{ Corticotherapy-PS* } \\
\hline No & 11 (34) & $67(58)$ & $29(36)$ & $83(69)$ \\
\hline
\end{tabular}

Table 3. continued

\begin{tabular}{|c|c|c|c|c|}
\hline & \multicolumn{4}{|c|}{ Analyzed population } \\
\hline & \multicolumn{2}{|c|}{$\begin{array}{l}\text { 16-day anti-CD20 } \\
\text { population }\end{array}$} & \multicolumn{2}{|c|}{ Overall population } \\
\hline & \multicolumn{2}{|l|}{ Group } & \multicolumn{2}{|l|}{ Group } \\
\hline & $\begin{array}{l}\mathrm{CP}+ \\
N(\%)\end{array}$ & $\begin{array}{l}\text { CP- } \\
N(\%)\end{array}$ & $\begin{array}{l}\mathrm{CP}+ \\
N(\%)\end{array}$ & $\begin{array}{l}\text { CP- } \\
N(\%)\end{array}$ \\
\hline Yes & $21(66)$ & $48(42)$ & $52(64)$ & $37(31)$ \\
\hline \multicolumn{5}{|l|}{ Tocilizumab } \\
\hline No & $31(97)$ & $106(92)$ & $75(93)$ & $115(96)$ \\
\hline Yes & $1(3)$ & $9(8)$ & $6(7)$ & $5(4)$ \\
\hline \multicolumn{5}{|c|}{ Azithromycin-hydroxychloroquine } \\
\hline No & $32(100)$ & $107(93)$ & $79(98)$ & $109(91)$ \\
\hline Yes & $0(0)$ & $8(7)$ & $2(2)$ & $11(9)$ \\
\hline \multicolumn{5}{|l|}{ Remdesivir } \\
\hline No & $29(91)$ & $107(93)$ & $72(89)$ & $117(98)$ \\
\hline Yes & $3(9)$ & $8(7)$ & $9(11)$ & $3(3)$ \\
\hline \multicolumn{5}{|c|}{ B-cell lymphoid neoplasm } \\
\hline $\begin{array}{l}\text { Chronic lymphocytic } \\
\text { leukemia }\end{array}$ & $6(19)$ & $11(10)$ & $13(16)$ & $18(15)$ \\
\hline $\begin{array}{l}\text { Diffuse large B-cell } \\
\text { lymphoma }\end{array}$ & $12(37)$ & $48(41)$ & $28(35)$ & $49(42)$ \\
\hline Follicular lymphoma & $6(19)$ & $32(28)$ & $23(28)$ & $22(18)$ \\
\hline $\begin{array}{l}\text { Marginal zone } \\
\text { lymphoma }\end{array}$ & $1(3)$ & $10(9)$ & $4(5)$ & $16(13)$ \\
\hline $\begin{array}{l}\text { Mantle cell } \\
\text { lymphoma }\end{array}$ & $5(16)$ & $13(11)$ & $11(14)$ & $11(9)$ \\
\hline $\begin{array}{l}\text { Waldenström } \\
\text { macroglobulinemia }\end{array}$ & $2(6)$ & $1(1)$ & $2(2)$ & $4(3)$ \\
\hline \multicolumn{5}{|c|}{$\begin{array}{l}\text { The proportion of treated patients differed greatly among the strata of } \\
\text { variables included in the propensity score such as age: } 54 \% \text { of treated in } \\
<65 \text { years vs. } 36 \% \text { in } \geq 65 \text { years in RCT-like population, } 48 \% \text { of treated in } \\
\text { absence of comorbidity vs. } 35 \% \text { in presence of comorbidity in the overall } \\
\text { population, } 14 \% \text { of treated in patients not receiving corticotherapy vs. } 30 \% \\
\text { in patients receiving corticotherapy. Moreover, this table shows that the } \\
\text { proportion of treated patients differed also for variables that could not be } \\
\text { included in the propensity score but defined sensitivity analysis popula- } \\
\text { tions such as wave, pre-exposure to anti-CD } 20 \text {, and area of hospitalization. } \\
C P \text { convalescent plasma, } A H \text { arterial hypertension, BMI body mass index, } P S^{*} \\
\text { included in the propensity score, } N \text { number of patients, WHO World Health } \\
\text { Organization, mAbs monoclonal antibodies. }\end{array}$} \\
\hline
\end{tabular}

risk of death was associated with B-depletion therapy such as antiCD20 or anti-CD19 mAbs in a recently published retrospective lymphoma cohort [16], previous B-cell therapy depletion was strongly associated with better OS in patients receiving convalescent plasma even after adjustment for confounding factors. Since most patients in our study $(87 \%)$ transfused with CCP had negative serology for COVID-19, we assume that such patients were unable to produce neutralizing SARS-CoV-2 antibodies due to the underlying hematological disease or the previously administered drugs targeting B-cells [19]. Subsequent transfer of neutralizing antibodies in such patients by means of CCP transfusion resulted in the control of viral replication and allowed for clinical recovery. The poor benefit of CCP transfusion in patients with plasma-cell or myeloid neoplasm as well as the uncertain benefit of CCP in the general COVID-19 population able to mount humoral response supports our hypothesis.

To further investigate the effect of CCP, we compared the subset of CCP-treated patients with B-cell lymphoid malignancy and COVID-19 to a similar cohort of patients who were treated with standard of care only. The methodology sought to control for 


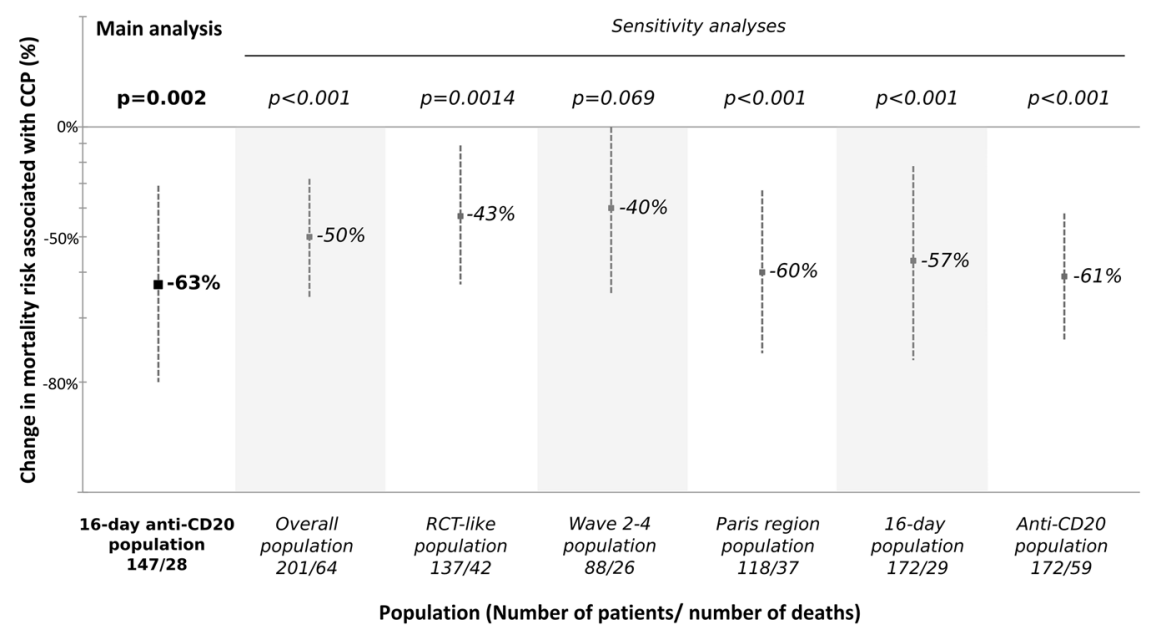

Fig. 5 Main et sensitivity analyses of mortality risk associated with COVID-19. Change (dot) and its 95\% confidence interval (line) in mortality risk associated with COVID-19 convalescent plasma (CCP) therapy from inverse-probability weighting (IPTW) model.

biases inherent to the observational design of this retrospective comparison; this included indication and immortal time biases. We showed that patients with B-cell lymphoid disease and preexposed to anti-CD20 therapy treated with CCP exhibited a significantly better survival probability than those who did not receive CCP. This important finding supports the results reported in a US-retrospective cohort [12]. as well as the positive trend observed in immunosuppressed patients (odds ratio (OR) 1.51 $(0.80-2.92))$ included in the recently reported REMAP-CAP trial [20], and confirms the essential role of convalescent plasma in the COVID-19 therapeutics landscape of patients with B-cell malignancy.

However, those results present several limitations and raise several questions. In our longitudinal cohort, the risk of death reaches $80 \%$ and $64 \%$ for myeloid neoplasm and plasma-cell neoplasm, respectively, that is twofold higher than reported in previous studies [1]. We must point out a higher COVID-19 severity with $34 \%$ of patients with myeloid and plasma-cell neoplasm requiring mechanical ventilation, whereas only $13 \%$ for B-cell neoplasm at the time of CCP. Similarly, previous studies reported a better outcome after early CCP transfusion in non-hospitalized patients [21]. Of note, we observed a lower OS in patients transfused within the first ten days after symptoms onset in univariable analysis, an association that disappeared in the multivariable analysis. A similar observation was made in the Recovery trial (in the CCP arm as well as the control arm) and may reflect more severe disease in patients hospitalized early in the course of the disease [22]. Furthermore, $62 \%$ of patients transfused earlier (within the first 10 days) transfusion in our cohort presented with myeloid or plasma-cell neoplasm.

In our retrospective nested analysis, data were collected prospectively from two data sources: one for patients exposed to CCP and another one for patients not exposed to CCP. Such a comparison could not identify the causal effect of treatment exposure with the level of proof provided by randomized clinical trials. We have tried to limit bias by using statistical methods to control indication bias (propensity score) and the immortal bias (time-lead analysis). The benefit of CCP appears to be robustly identified in all our sensitivity analyses. In addition, the main analysis, which allows for stricter controls on indication and immortal bias, use of 16-day landmark and IPTW identifies the strongest effect. We also have no data on the type of viral strain that infected the patients who received CCP, and thus could not analyze the impact of virological parameters in the response to CCP. However, during the inclusion period, SARS-CoV-2 strains circulating in France were mainly the Wuhan original strain and its
Alpha variant. Therefore, we cannot extend our results to the Delta variant of concern that is currently becoming dominant worldwide. Plasma from convalescent and vaccinated donors exhibit high titer crossvariant antibodies that may provide a higher efficacy than the CCP used in our study [23-25]. We presently favor the issuing of such CCP for the treatment of immunosuppressed patients with B-cell malignancies [26].

Although our study generates some strong arguments in favor of the use of CCP in B-cell depleted COVID-19 patients, several recent issues need to be considered. Indeed, initiation of the anti-SARS-CoV-2 vaccination [27], the availability and use of antispike mAbs in patients at risk of developing a severe form of COVID-19 [28], and the emergence of SARS-CoV-2 variants have changed the course of COVID-19 outbreak. Firstly, none of the patients in both cohorts (CCP-treated and non-CCP-treated) were vaccinated against SARS-CoV-2. Although prospective randomized trials strongly support the efficacy of vaccination in the general population, results are less favorable in immunosuppressed patients, especially patients with chronic lymphocytic leukemia or multiple myeloma who exhibit a lower serological response despite two administrations of BNT162b2 mRNA COVID-19 vaccine $[5,29,30]$. Further investigations are needed to evaluate the efficacy of vaccination on mortality linked to COVID-19 in such patients. Secondly, use of anti-spike mAb opened a new perspective, especially in frail patients with a reduction of related hospitalization or death in mild to moderate COVID-19 patients [31]. Besides the cost of such an approach (over 2000 euros per administration compared to $\approx 120$ euros/CCP) and possibly limited availability, immune escape mutations have been described especially in patients with B-cell lymphoid disease, justifying a successful treatment rescue with CCP $[32,33]$. In light of this, the emergence of variants due to protracted shedding or therapyrelated selection $[34,35]$ remains the most important challenge to face. In our series, although we did not assess the SARS-CoV-2 lineages, we did not observe a difference in OS between the three epidemic outbreaks.

In conclusion, among patients with hematological malignancy and COVID-19, CCP represents an interesting approach, especially in patients with B-cell lymphoid neoplasm and who are pretreated with anti-CD20 mAbs. Importantly, such patients have a poor response to vaccination and may present an escape variant due to prolonged shedding or anti-spike mAbs administration. The role of CCP in the treatment of COVID-19 patients unable to mount a humoral response could be strengthened if confirmed in a randomized prospective trial and should also be discussed in light of the increasing availability of anti-spike mAbs. 


\section{REFERENCES}

1. Vijenthira A, Gong IY, Fox TA, Booth S, Cook G, Fattizzo B, et al. Outcomes of patients with hematologic malignancies and COVID-19: a systematic review and meta-analysis of 3377 patients. Blood. 2020;136:2881-92.

2. Robilotti EV, Babady NE, Mead PA, Rolling T, Perez-Johnston R, Bernardes M, et al. Determinants of COVID-19 disease severity in patients with cancer. Nat Med. 2020;26:1218-23.

3. Choi B, Choudhary MC, Regan J, Sparks JA, Padera RF, Qiu X, et al. Persistence and evolution of SARS-CoV-2 in an immunocompromised host. $\mathrm{N}$ Engl J Med. 2020;383:2291-3.

4. Michot JM, Hueso T, Ibrahimi N, Pommeret F, Willekens C, Colomba E, et al. Severe COVID-19 in patients with hematological cancers presenting with viremia. Ann Oncol. 2021;32:1297-300.

5. Herishanu Y, Avivi I, Aharon A, Shefer G, Levi S, Bronstein Y, et al. Efficacy of the BNT162b2 mRNA COVID-19 vaccine in patients with chronic lymphocytic leukemia. Blood. 2021;137:3165-73.

6. Malard F, Gaugler B, Gozlan J, Bouquet L, Fofana D, Siblany L, et al. Weak immunogenicity of SARS-CoV-2 vaccine in patients with hematologic malignancies. Blood Cancer J. 2021;11:1-8.

7. O'Donnell MR, Grinsztejn B, Cummings MJ, Justman JE, Lamb MR, Eckhardt CM, et al. A randomized double-blind controlled trial of convalescent plasma in adults with severe COVID-19. J Clin Invest. 2021;131:e150646.

8. Bar KJ, Shaw PA, Choi GH, Aqui N, Fesnak A, Yang JB, et al. A randomized controlled study of convalescent plasma for individuals hospitalized with COVID19 pneumonia. J Clin Invest. 2021;131:e155114.

9. Avendaño-Solá $C$, Ramos-Martínez A, Muñez-Rubio E, Ruiz-Antorán B, Malo de Molina R, Torres $F$, et al. A multicenter randomized open-label clinical trial for convalescent plasma in patients hospitalized with COVID-19 pneumonia. J Clin Invest. 2021;131:e152740.

10. Janiaud P, Axfors C, Schmitt AM, Gloy V, Ebrahimi F, Hepprich M, et al. Association of convalescent plasma treatment with clinical outcomes in patients with COVID19: a systematic review and meta-analysis. JAMA. 2021;325:1185-95.

11. Hueso T, Pouderoux $C$, Péré $H$, Beaumont A-L, Raillon L-A, Ader F, et al. Convalescent plasma therapy for B-cell-depleted patientswith protracted COVID-19. Blood. 2020;136:2290-5.

12. Thompson MA, Henderson JP, Shah PK, Rubinstein SM, Joyner MJ, Choueiri TK et al. Association of convalescent plasma therapy with survival in patients with hematologic cancers and COVID-19. JAMA Oncol. 2021;7:1167-75.

13. Calip GS, Miksad RA, Sarkar S. Time-related biases in nonrandomized COVID19-era studies using real-world data. JAMA Oncol. 2021;7:1175-7.

14. Gallian P, Pastorino B, Morel P, Chiaroni J, Ninove L, de Lamballerie X. Lower prevalence of antibodies neutralizing SARS-CoV-2 in group O French blood donors. Antiviral Res. 2020;181:104880.

15. WHO Working Group on the Clinical Characterisation and Management of COVID-19 infection. A minimal common outcome measure set for COVID-19 clinical research. Lancet Infect Dis. 2020;20:e192-97.

16. Duléry R, Lamure $S$, Delord M, Di Blasi R, Chauchet A, Hueso T, et al. Prolonged inhospital stay and higher mortality after Covid-19 among patients with nonHodgkin lymphoma treated with B-cell depleting immunotherapy. Am J Hematol. 2021;96:934-44.

17. Joyner MJ, Wright RS, Fairweather D, Senefeld JW, Bruno KA, Klassen SA, et al. Early safety indicators of COVID-19 convalescent plasma in 5000 patients. J Clin Invest. 2020;130:4791-7.

18. Passamonti F, Cattaneo C, Arcaini L, Bruna R, Cavo M, Merli F, et al. Clinical characteristics and risk factors associated with COVID-19 severity in patients with haematological malignancies in Italy: a retrospective, multicentre, cohort study. Lancet Haematol. 2020;7:e737-45.

19. Murphy MF, Dzik S. COVID-19, plasma, and hypogammaglobulinemia. Blood 2020;136:2245-6.

20. Writing Committee for the REMAP-CAP Investigators. Effect of convalescent plasma on organ support-free days in critically III patients with COVID-19: a randomized clinical trial. JAMA. 2021;326:1690-702.

21. Libster R, Pérez Marc G, Wappner D, Coviello S, Bianchi A, Braem V, et al. Early high-titer plasma therapy to prevent severe COVID-19 in older adults. N Engl J Med. 2021;384:610-8.

22. RECOVERY Collaborative Group. Convalescent plasma in patients admitted to hospital with COVID-19 (RECOVERY): a randomised controlled, open-label, platform trial. Lancet. 2021;397:2049-59.

23. Tauzin A, Nayrac M, Benlarbi M, Gong SY, Gasser R, Beaudoin-Bussières G, et al. A single dose of the SARS-CoV-2 vaccine BNT162b2 elicits Fc-mediated antibody effector functions and T cell responses. Cell Host Microbe. 2021;29:1137.e6.

24. Stamatatos L, Czartoski J, Wan YH, Homad LJ, Rubin V, Glantz H, et al. mRNA vaccination boosts cross-variant neutralizing antibodies elicited by SARS-CoV-2 infection. Science. 2021;372:1413-8.
25. Liu C, Ginn HM, Dejnirattisai W, Supasa P, Wang B, Tuekprakhon A, et al. Reduced neutralization of SARS-CoV-2 B.1.617 by vaccine and convalescent serum. Cell. 2021;184:4220.e13.

26. Ordaya EE, Abu Saleh OM, Stubbs JR, Joyner MJ. Vax-plasma in patients with refractory COVID-19. Mayo Clin Proc. 2022;97:186-9.

27. Polack FP, Thomas SJ, Kitchin N, Absalon J, Gurtman A, Lockhart S, et al. Safety and efficacy of the BNT162b2 mRNA COVID-19 vaccine. N Engl J Med. 2020;383:2603-15.

28. Horby PW, Mafham M, Peto L, Campbell M, Pessoa-Amorim G, Spata E, et al. Casirivimab and imdevimab in patients admitted to 4 hospital with COVID-19 (RECOVERY): a randomised, controlled, open-label, platform trial. medRxiv [Preprint]. 2021.

29. Thakkar A, Gonzalez-Lugo JD, Goradia N, Gali R, Shapiro LC, Pradhan K, et al. Seroconversion rates following COVID-19 vaccination among patients with cancer. Cancer Cell. 2021;39:1081.e2.

30. Terpos E, Trougakos IP, Gavriatopoulou M, Papassotiriou I, Sklirou AD, NtanasisStathopoulos I, et al. Low neutralizing antibody responses against SARS-CoV-2 in older patients with myeloma after the first BNT162b2 vaccine dose. Blood. 2021;137:3674-6.

31. Weinreich DM, Sivapalasingam S, Norton T, Ali S, Gao H, Bhore R, et al. REGNCOV2, a neutralizing antibody cocktail, in outpatients with COVID-19. N Engl J Med. 2021;384:238-51.

32. Pommeret F, Colomba J, Bigenwald C, Laparra A, Bockel S, Bayle A, et al. Bamlanivimab+etesevimab therapy induces SARS-CoV-2 immune escape mutations and secondary clinical deterioration in COVID-19 patients with B-cell malignancies. Ann Oncol. 2021;32:1445-7.

33. Lohr B, Niemann D, Verheyen J. Bamlanivimab treatment leads to rapid selection of immune escape variant carrying the E484K mutation in a B.1.1.7-infected and immunosuppressed patient. Clin Infect Dis. 2021;73:2144-5.

34. Kemp SA, Collier DA, Datir RP, Ferreira IATM, Gayed S, Jahun A, et al. SARS-CoV-2 evolution during treatment of chronic infection. Nature. 2021;592:277-82.

35. Martinot M, Jary A, Fafi-Kremer S, Leducq V, Delagreverie $H$, Garnier $M$, et al Emerging RNA-dependent RNA polymerase mutation in a remdesivir-treated $\mathrm{B}$ cell immunodeficient patient with protracted coronavirus disease 2019. Clin Infect Dis. 2021;73:e1762-e1765.

\section{ACKNOWLEDGEMENTS}

The authors would like to acknowledge all the clinicians from the HEMOPLASM study group for their participation in data collection: Julie Abraham, Hafid Ait Oufella, Kevin Alexandre, Elie Azoulay, Benoit Bailly, Ana Berceanu, Anne Bergeron, Camille Bigenwald, Corinne Merle de Boever, Kevin Bouiller, Ines Boussen, Fabrice Bruneel, Yannick Brunin, Côme Bureau, Georges-Daniel Calcaianu, Marion Calmette, Jérémy Castanera, Agnes Chapelet, Julien Colle, Etienne Crickx, Laure Crognier, Donatien de Seissan De Marigna, Maxime Desgrouas, Ines Devred, Guillaume Dumas, Stanislas Faguer, Anne-Marie Fillet, Guillaume Franchineau, Victor Gerber, Romain Gueneau, Otto Hartman, Romain Jouffroy, Marie-Anne Lafont, Paul Le Turnier, Thomas Longval, Paul Loubet, Mathieu Mahevas, Mylène Maillet, Martin Martinot, Arsène Mekinian, Giovanna Melica, Fatiha Merabet, Joy Mootien, Caroline Morbieu, Camille Munck, Mai-Anh Nay, Nathalie Pansu, Arthur Pavot, Lucas Perez, Thomas Perpoint, Philippe Petua, Emilie Piet, Julien Poissy, Fanny Pommeret, Caroline Pouplet, Caroline Protin, Pascale Richard, Elodie Rivière, Adrien Robine, Claire Rouzaud, Julien Saussereau, Maleka Schenck, Tali-Anne Szwebel, Jean-François Timsit, Axel Ursenbach, Geoffroy Venton, Virginie Vitrat, Florent Wallet, Charlotte Wemmert, Benjamin Wyplosz, and Elise Yvin. We also thank Dorothée Fey, who managed the weekly multidisciplinary convalescent plasma review meetings and participated in the data collection; the CCP donors; Etablissement Français du Sang personnel who managed CCP collection and testing; as well as the patients who consented to the anonymous use of their clinical data for this study.

\section{AUTHOR CONTRIBUTIONS}

$\mathrm{TH}, \mathrm{KL}, \mathrm{PT}, \mathrm{CB}$, and RD designed the study and wrote the manuscript. TH, SG and EL analyzed data and performed statistical analyses. TH, A-SG, JP, J-LM, LIL, EG, LS, AG, FP, SI, $\mathrm{PM}, \mathrm{SL}, \mathrm{OH}, \mathrm{AG}-\mathrm{B}$, and NF managed and followed-up patients, collected data, and revised and approved manuscript.

\section{FUNDING}

This study was supported by the program Emergency Support Instrument (ESI) of the European Commission (project CCPEFS, grant number 101021793) and Sorbonne University. 
1034

COMPETING INTERESTS

The authors declare no competing interests.

\section{ADDITIONAL INFORMATION}

Supplementary information The online version contains supplementary material available at https://doi.org/10.1038/s41375-022-01511-6.
Correspondence and requests for materials should be addressed to Thomas Hueso or Karine Lacombe.

Reprints and permission information is available at http://www.nature.com/ reprints

Publisher's note Springer Nature remains neutral with regard to jurisdictional claims in published maps and institutional affiliations. 